\title{
Políticas públicas municipais e economia solidária*
}

\author{
Municipal public policy and social economy \\ Politique publique municipale et économie sociale \\ Política pública municipal y economía social
}

\author{
Fernanda Henrique Cupertino Alcântara** \\ (fernanda.alcantara@ufjf.edu.br)
}

Recebido em 12/10/2012; revisado e aprovado em 06/07/2013; aceito em 19/09/2013

\begin{abstract}
Resumo: A Economia Solidária ganhou relevância nas três últimas décadas e tornou-se objeto de muitas políticas públicas brasileiras de geração de renda. Neste artigo discuto as especificidades das políticas públicas de geração de renda, mecanismos fundantes, estruturas organizacionais e modelos possíveis, considerando trabalhos teóricos e de pesquisas de campo publicados até o momento como contraponto às particularidades sugeridas.

Palavras-chave: Políticas públicas. Economia solidária. Cooperativismo.

Abstract: The Solidarity Economy has gained prominence in the last three decades and has become the object of many Brazilian public policies for income generation. In this article I discuss the specifics of public policies for income generation, founding mechanisms, organizational structures and possible models, considering theoretical and field research published to date as a counterpoint to the particularities suggested.

Key words: Public policies. Solidarity economy. Cooperatives.

Résumé: L'économie solidaire a gagné en importance au cours des trois dernières décennies et est devenu l'objet de nombreuses politiques publiques brésiliennes pour la génération de revenus. Dans cet article, je discute les spécificités des politiques publiques pour la génération de revenus, les mécanismes fondateurs, les structures organisationnelles et des modèles possibles, compte tenu de la recherche théorique et de terrain publié à ce jour comme un contrepoint aux particularités proposées.

Mots-clés: Politiques publiques. Economie solidaire. Les coopératives.

Resumen: La Economía Solidaria ha ganado importancia en las últimas tres décadas y se ha convertido en objeto de muchas de las políticas públicas brasileñas de generación de ingresos. En este artículo el autor analiza los aspectos específicos de las políticas públicas para la generación de ingresos, mecanismos fundacionales, las estructuras organizativas y los posibles modelos, teniendo en cuenta la investigación teórica y de campo publicado hasta la fecha como un contrapunto a las particularidades sugeridas.

Palabras clave: Políticas públicas. Economía solidaria. Cooperativas.
\end{abstract}

\section{Introdução}

A Economia Solidária (ES) ganhou relevância principalmente nas três últimas décadas e, talvez, em função disso, tem sido estudada por um número significativo de pesquisadores desde então. Entretanto, apenas recentemente, tem-se discutido com maior frequência sobre a possibilidade de se aumentar o número de empreendimentos cooperativos, bem como sobre as formas de incentivá-los, por meio de políticas públicas. Por Economia Solidária, entendo o conjunto de práticas cooperativas, com solidarização de capital e com organização autogestionária, de caráter produtivo, prestação de serviços, consumo, habitação ou ramo agropecuário, com ou sem registro formal, podendo adotar formas como mutirão, associação, cooperativa, grupo de produtores informais e outros.

A proposta de promover os empreendimentos de Economia Solidária por meio de políticas públicas assumiu diversos formatos e foi encampada por políticos de origens diversas, embora tenha ocorrido com maior frequência nos governos do Partido dos Trabalhadores (PT). Parte dessas experiências foram reunidas na Rede de Gestores Públicos de Economia Solidária ${ }^{1}$, a qual, por sua vez, é um dos instrumentos da política pública de incentivo ao cooperativismo, promovida pelo governo federal (ALCÂNTARA, 2005), com

\footnotetext{
${ }^{1}$ Trata-se de uma Rede formada pelo Governo Federal, vinculada à Secretaria Nacional de Economia Solidária (SENAES), do Ministério do Trabalho e do Emprego.
}

\footnotetext{
*Este trabalho é parte do Capítulo 02 de minha tese de doutoramento em Sociologia defendida no IUPERJ, em 2008, foi parcialmente publicado na XIV SBS/2009 e amplamente modificado para publicação neste periódico.

** Universidade Federal de Juiz de Fora, Governador Valadares, MG, Brasil.
} 
o intuito de mapear e sistematizar os dados relativos a tais projetos, além de avaliá-los, comparando-os ao plano nacional de estímulo ao cooperativismo e empreendimentos de natureza similar (SINGER, 2009). Lógico que tal política tende a mudar consideravelmente a partir de 2012 com o advento da nova Lei de Cooperativas. Não obstante, há que se destacar a ampla aplicação que os projetos de geração de renda têm alcançado, tanto nos programas de governo quanto nos de gestão administrativa. Em certo sentido, ocorre mesmo uma "via de mão dupla", na medida em que temos teorização e aplicação acontecendo simultaneamente. A partir dessa constatação, entendo que é pertinente a avaliação, o estudo da institucionalização e a capacidade institucionalizadora de tais políticas.

\section{Políticas públicas}

A expansão e fortalecimento dos empreendimentos de Economia Solidária são constantemente atrelados à formulação e implementação de políticas públicas. Essa vinculação não ocorre por acaso. Expandir e fortalecer uma prática remete à institucionalização desta, e políticas públicas constituemse, a princípio, em mecanismos eficientes para cumprir tal tarefa. A justificativa para o esforço empreendido nesse sentido pode não parecer óbvia para os que não estão familiarizados com o tema. O formato de políticas públicas (PPs) pode e tem sido utilizado para institucionalizar hábitos, quaisquer que sejam eles, mas para que obtenham efetividade deve-se considerar - além da dinâmica interna própria a estas - o contexto (social, político e histórico) no qual elas serão inseridas ou para os quais foram criadas.

Considera-se, portanto, que as PPs sejam capazes de atuar nos dois vetores componentes do processo de institucionalização, quais sejam: a regulamentação e a rotinização da prática (ALCÂNTARA, 2005). Contudo, tal como exposto anteriormente, acredito que para avaliarmos a possibilidade de institucionalização de uma determinada política pública é necessário, antes de tudo, esclarecer qual é a dinâmica interna da administração concernente, levando-se em consideração, para tanto, a origem dos recursos utilizados para gerir uma localidade, sua destinação, regulamentação e possibilidades de "manobras" (alteração) dentro da estrutura normativa instaurada. Requer também um reconhecimento sócio-histórico da realidade atual, vendo-a como algo contingencial. Por essa razão, ao considerarmos que, nos últimos anos, houve uma tendência a transferir para os municípios a responsabilidade de resolver problemas relativos à geração de emprego e renda, fenômeno este que denominei municipalização das políticas públicas de geração de renda (ALCÂNTARA, 2008), entendo que, para analisar políticas públicas dessa natureza e no âmbito municipal, devemos considerar a "dinâmica interna da administração pública", mais especificamente, das municipalidades. Tal consideração permite-nos discutir os entraves inerentes às $\mathrm{PP}(\mathrm{s})$, o que, por sua vez, joga luz sobre a própria discussão da institucionalização das práticas de Economia Solidária apoiadas pelos governos e pela sociedade civil organizada.

\section{Conceito e "estado da arte"}

Em primeiro lugar, precisamos conceituar o termo política pública e discuti-lo nas três esferas de governo (federal, estadual e municipal), para depois especificá-lo. Como bem lembra Souza (2006), a PP é uma produção dos governos, e seu debate está inserido num contexto maior que abarca o Estado e suas instituições. Portanto, comumente, estudar as $\mathrm{PP}(\mathrm{s})$ consiste em analisar a ação dos governos. Ressalva seja feita ao fato de que também se compreende a ação dos governos pelo que deixam de fazer. Pode-se, no entanto, questionar que, embora o objeto da "disciplina" políticas públicas seja o governo em ação, não se tem um conceito do que seja a própria política pública. Mas isso não é tudo. A PP não resulta apenas da ação ou não ação dos governos, mas também tem origem na sociedade civil organizada. E, no plano governamental, as $\mathrm{PP}(\mathrm{s})$ são produzidas pelo Executivo, Legislativo e Judiciário, de forma conjunta ou isoladamente.

Algumas considerações podem ser adicionadas a essa curta delimitação conceitual e, como referência, adotei as características citadas por Souza (2006, p. 36), quais sejam: 1) a PP demonstra o que o governo pretende fazer e o que realmente faz; 2 ) abarca "níveis 
de decisão" e atores variados, além de não se restringir a relações formais como determinantes de seus resultados; 3 ) sua complexidade impede-nos de restringi-la a "leis e regras"; 4) pode até gerar resultado em curto prazo, mas seu perfil é de uma ação cujos resultados só aparecem em longo prazo; 5) não se esgota na proposição da ação, mas também em sua "implementação, execução e avaliação". Quanto às características apontadas, creio que alguns complementos são necessários. A primeira afirmação só procede na medida em que toda PP requer um programa de ação, o qual pode ser cumprido ou descumprido. A segunda afirmação dessa autora traz à baila a questão do poder de ação relativo ao controle da máquina administrativa, o qual incorpora muito mais uma noção de "vontade política", do que propriamente estrutura formal para fazê-lo. Lembra também o fato de que, embora geral, essa estrutura é que o autoriza a agir. $\mathrm{O}$ terceiro ponto mantém escondida a noção de que esses objetivos podem ser ou não declarados. Já a quarta afirmação permite conjecturar que, por ser "uma política de longo prazo", sua eficiência encontra-se principalmente na permanência ao longo do tempo, ponto caro à minha argumentação.

Voltando à conceituação de $\mathrm{PP}(\mathrm{s})$, Sampaio e Araújo Jr. (2006) as entendem como respostas que o Estado fornece à sociedade para problemas públicos. Em outras palavras, são ações públicas que visam regular problemas sociais. Os autores entendem que a política é pública porque tem "interesses públicos e fins públicos", o que não impede que organizações fora do Estado, como as ONGs (leia-se: associações sem fins lucrativos, OSCIPs, OSs e outros) $)^{2}$, embora se submetam à regulação estatal, também desenvolvam políticas públicas. No caso específico deste trabalho, tal concepção não se faz adequada, visto que o recorte da pesquisa está enquadrado especificamente na Administração Pública. Adotando-se essa perspectiva, quanto à composição, as $\mathrm{PP}(\mathrm{s})$ contemplam: 1) atores; 2) conteúdo; 3) contexto; e 4) processo, o qual se divide em construção da agenda, formulação

\footnotetext{
${ }^{2}$ ONGs são Organizações Não Governamentais, OSCIPs são Associações que recebem uma declaração reconhecendo-as como de interesse público, por isso são Organizações da Sociedade Civil de Interesse Público, e as OSs são as Organizações Sociais.
}

e implementação. Tal consideração permite visualizar a complexidade dos elementos e da dinâmica inerentes à PP. Contudo, nenhuma novidade até a consideração de que esta é um processo, que engloba momentos anteriores e posteriores a si mesma, por esta razão, a grande sina, na verdade, encontra-se na relação entre a formulação e a implementação dessas políticas.

Outra contribuição importante é a percepção de que não só a área de atuação das $\mathrm{PP}(\mathrm{s})$ determina seu escopo, como também o perfil da administração pública, muitas vezes determinado pelos, assim chamados, equipamentos públicos, serviços, disputas políticas, locação de recursos, etc. Como interessa o desenvolvimento no âmbito das intervenções públicas, implica considerar: o contexto (que é o ambiente social, histórico, político e ideológico no qual a PP visa atuar); a posição dos atores (com relação à PP, se de oposição ou apoio, além da posição que os atores estabelecem entre si); o conteúdo das políticas públicas (principalmente os resultados com relação ao alcance das metas propostas; a coerência entre objetivos propostos e programas, projetos e ações desenvolvidos; a perspectiva político-social). Como já disse anteriormente, o último item nesse grupo é o processo, já que a PP é construída em fases. Para Sampaio e Araújo Jr. (2006), essas fases são: a construção da agenda (em que se definem as prioridades, que sofrem influência da tomada de decisão, do espaço político e temporal de uma gestão, do tipo de participação social existente); $a$ formulação da política pública (na qual se estabelecem mecanismos e ações supostamente capazes de possibilitar o alcance das metas e objetivos propostos, além de atentar para as possibilidades de êxito); e a implementação da política pública (os autores consideram que é "pôr a política em ação", ou seja, executar o que foi negociado).

Adotando o conceito de PP como o produto da ação do Estado, voltemos agora a atenção para a sua dinâmica e elementos constitutivos, já que, para o Estado "agir", são indispensáveis alguns requisitos formais e informais, tanto dentro do processo como externamente. Quanto à dinâmica da PP, deve-se analisar o que a condiciona antes de constituir-se enquanto tal. O primeiro elemento, portanto, é entender como um assunto 
ou linha de ação ganha espaço na agenda política de "quem" está ocupando os cargos do Executivo ${ }^{3}$.

Numa linha de raciocínio bastante parecida, por considerarem os mesmos elementos, Couto e Abrucio (2003) alertam para os condicionamentos políticos ao encaminhamento da agenda de políticas públicas. Para delimitar aqueles, consideram os atores e as instituições e, para estas, a política econômica somada às emendas constitucionais ${ }^{4}$. Os condicionamentos políticos são elementos determinantes para a dinâmica das PP(s) e a "agenda" também, mas eles não são constitutivos destas, embora sejam inerentes ao processo que as engendra. Um condicionamento político importante diagnosticado por minha pesquisa de tese (ALCÂNTARA, 2008), por exemplo, foi o fato de os projetos de geração de renda e de formação de cooperativas constarem como "promessas de campanha" e "programa de governo" dos prefeitos que administravam os municípios estudados. Desse modo, concordo com os autores, na medida em que tal condicionamento estimulou a reserva de espaço para essa questão dentro da agenda política, o que considero um primeiro passo para a criação de $\mathrm{PP}(\mathrm{s})$, independentemente se tal fato partiu de mobilização popular, da própria orientação ideológica do partido ou devendo-se a outras razões.

Da dinâmica seguimos para o estudo das PP(s) no Brasil, uma espécie de "estado da arte", deixando para um momento posterior a discussão sobre a fase da implementação. Faria (2003) lembra que as PP(s), antes de serem institucionalizadas como disciplina, estudavam apenas o processo decisório, tomando como variáveis explicativas principalmente as relações de poder. Isso acarretou o esquecimento do processo de implementação devido, em parte, à não preocupação com a avaliação dos resultados obtidos com as PP(s). Para ele, pior do que isso é o fato de só muito recentemente elementos como as redes passarem a constar na agenda dos estudos sobre $\mathrm{PP}(\mathrm{s})$, enquanto outros elementos como as

\footnotetext{
${ }^{3}$ Lembrando que este artigo restringe-se à análise das $\mathrm{PP}(\mathrm{s})$ estatais.

${ }^{4}$ Fala-se em emendas constitucionais porque os autores estão discutindo a ação do Executivo e Legislativo federais. Embora isso pudesse ser aplicado também no âmbito estadual.
}

ideias e o conhecimento sequer integram ou são considerados pela maioria dos pesquisadores. Por sua vez, Arretche (2003) argumenta que, embora tenha ocorrido a institucionalização da PP como sub-disciplina no Brasil, tem-se observado uma baixa capacidade de acumulação do conhecimento e ausência de explicitação dos pressupostos teóricos utilizados para orientar cada pesquisa.

Reafirmando essas concepções sobre o desenvolvimento do estudo das PP(s), Souza (2003b, p.16) diagnostica os seguintes problemas: 1) escassa acumulação de conhecimento na área e escasso diálogo entre os trabalhos; 2) excesso de estudos de caso, com forte característica empírica, sem um desenvolvimento analítico concomitante (chamado por ela de "crescimento horizontal"); 3) o problema da proximidade com os órgãos que produzem as $\mathrm{PP}(\mathrm{s})$, o que pode distanciar as pesquisas ainda mais da percepção analítica, dando-lhes um caráter normativo, além de definir os temas de estudo, provocando repetição exaustiva de determinados assuntos e ausência total de outros. Para resolver esses obstáculos Souza (2003a) ressalta que é importante atentar para a "natureza do problema" que se busca resolver, estudar as "redes de implementação", desenvolver "tipologias analíticas" e identificar variáveis intervenientes. Além disso, ela argumenta que os diversos rótulos usados recorrentemente nos estudos de PP(s) deveriam ser submetidos a testes empíricos e teorias "embasadas" para verificar sua validade ${ }^{5}$. As pesquisas comparativas também precisariam ganhar espaço e serem estimuladas, principalmente no que tange às diferenças de implementação observadas entre os Estados da federação. Freitas e Freitas (2011), por exemplo, entendem que o Programa de Combate à Pobreza do governo de Minas Gerais, estimulou a criação de empreendimentos coletivos, mas sem cuidar do processo de mobilização para a política pública, o que acarretou problemas para a sustentabilidade desta.

Outro enfoque ressalta a questão do financiamento. Como vimos, o desenho da PP não está submetido apenas e restritivamente ao objetivo de atingir uma determinada finalidade, portanto não pode ser reduzido a uma

\footnotetext{
${ }^{5}$ Como exemplo a autora cita os termos clientelismo, paroquialismo e patrimonialismo.
} 
questão de racionalidade neutra e universal. Por esse motivo é necessário entender qual o processo relativo a esse tipo específico de despesa. Souza (2003b) reforça a preocupação com as relações que interferem na formulação e execução das PP(s), ressaltando os conflitos de interesse e a cooperação, abrindo espaço, inclusive, para a importância dos recursos orçamentários. Também ressalta o fato de que, "na maioria das vezes, a política pública requer aprovação legislativa" (SOUZA, 2003b, p. 14), o que implica necessário diálogo entre Executivo e Legislativo. Esse elemento pode parecer óbvio, mas é constantemente negligenciado por pesquisadores da área.

Côrtes (2003) trabalha outro item caro ao entendimento das $\mathrm{PP}(\mathrm{s})$, qual seja a mudança política, isto é, a alternância de grupos no poder. De acordo com ela, a questão da mudança política na gestão administrativa, no caso, o Executivo, não interferiu na institucionalização do processo de descentralização da tomada de decisão, promovido, por exemplo, pelo Estado do Rio Grande do Sul. Contudo, reitera a necessidade de coalizão política para permitir a governabilidade e a capacidade de implementar PP(s). O modelo institucional variou em função de mudanças quanto aos atores sociais, suas atribuições e acesso ao centro de decisão, para garantir os interesses dos grupos que ocuparam o governo do Estado. Porém o desenho institucional é que condicionou a governabilidade, principalmente nos casos em que o Executivo contou com uma minoria na Assembleia Legislativa, tornandose uma forma de legitimar as "prioridades" da agenda política confeccionada por este. Essa autora constatou, portanto, que, embora quatro grupos diferentes tenham se alternado no poder entre 1991 e 2003, utilizando-se de meios específicos para a implementação, isso não impediu a continuidade da PP, provavelmente devido ao apelo popular, mas mesmo a permanência dos programas não conseguiu impedir a mudança no desenho institucional destes. Ainda sobre a institucionalização das próprias PP(s), Milani (2006, p. 202) afirma que elas não se perpetuarão na "ausência de instâncias formais e institucionais que assegurem sustentabilidade à gestão participativa". Consequentemente, é importante que experiências dessa natureza consigam constituir um "ciclo político".
$\mathrm{Na}$ "contramão" desse argumento acerca da institucionalização das $\mathrm{PP}(\mathrm{s})$, Setzler (2003) demonstra que o apelo popular por reformas nesse setor tem sua capacidade determinada, em grande medida, pelo capital socioeconômico, capital sociocultural e conhecimento político. O dilema da ação coletiva é vislumbrado nesse sentido, já que, embora os eleitores, em sua maioria, sejam beneficiados por políticas sociais, sendo os bens públicos de caráter não exclusivo, parte daqueles busca benefícios individuais por meio de relações clientelis$\operatorname{tas}^{6}$. Tal contexto acaba por incentivar "políticas clientelistas" e inibir o surgimento de "políticos reformistas". Mas Setzler conclui, diante dos dados relativos às capitais por ele estudadas, que muitos eleitores conseguem superar o dilema da ação coletiva por meio do que ele denominou "condições adicionais". Em outras palavras, essa superação "ocorre quando esses indivíduos têm acesso a recursos socioeconômicos e ao capital sociocívico" (SETZLER, 2003, p. 141). Desse modo, o autor relaciona "recursos sociais" às "motivações eleitorais" ${ }^{\prime \prime}$. Para que as PP(s) alcancem os resultados esperados, Setzler (2003) afirma ser necessária a construção de "círculos virtuosos" (BONFIM; SILVA, 2003). Como exemplo tem-se o Orçamento Participativo (OP), o qual permite a expansão dos níveis de participação política entre os pobres. Mas Setzler (2003, p. 157) aponta que, “[...] tão importante quanto a participação é a educação dos cidadãos sobre a política local, o orçamento e o financiamento do governo municipal", visto que os indivíduos mais carentes estão pouco preparados para demandar políticas reformistas, devido ao imediatismo de suas necessidades.

A ideia de "círculos virtuosos" é apropriada neste trabalho para reafirmar a premissa de que existem "elementos fixadores" que promovem a transição de um hábito ao outro, por provocar a familiaridade com atitudes e modos de interpretar o mundo e que,

\footnotetext{
${ }^{6}$ Sobre a teoria da escolha racional e sua relação com a ação coletiva ver Araújo (2011).

${ }^{7}$ Uma correlação um pouco suspeita, feita pelo autor, é a de que existe mais clientelismo nas eleições para vereadores do que para prefeito, já que o autor "esquece" que, em muitos casos, quem dá os meios ao vereador é o candidato a prefeito, mantendo com ele um novo tipo de clientelismo, que será reproduzido, possivelmente, na esfera estadual e federal.
} 
até então, eram estranhos aos envolvidos. Além disso, a questão do imediatismo das necessidades ajuda a situar o processo de transição, facilitando que se propague, e a estabelecer mecanismos para que não ocorra neste um retrocesso, devido à carência material do mínimo necessário para persistir na nova experiência.

Complementarmente, Milani (2006, p. 181) afirma que o modelo burocrático de Administração Pública está em crise junto com o próprio modelo de Estado. Para se alcançar a efetividade das $\mathrm{PP}(\mathrm{s})$, os políticos têm lançado mão de:

[...] estratégias de descentralização, adoção de mecanismos de responsabilização dos gestores públicos (responsiveness e accountability), a gestão por resultados, o incremento do controle social, além de dispositivos de participação social que visam a envolver cidadãos e organizações da sociedade civil na gestão pública.

Diante da suposta crise da burocracia e do Estado, cresce nos anos de 1990 o discurso sobre a necessidade da participação dos cidadãos na construção de $\mathrm{PP}(\mathrm{s})$. Ocorre, com isso, uma maior democratização do processo de formulação destas. Com a reforma interna do Estado, nos anos 80 e 90, buscou-se a "boa governança", com base em fundamentos mais econômicos do que políticos, "coincidindo com a redemocratização política" do país. Nesse contexto é que surge a premissa de que a participação popular nos processos inerentes às $\mathrm{PP}(\mathrm{s})$ as tornam mais democráticas, combinando-se, assim, com o movimento de descentralização (ALCÂNTARA, 2010; ALCÂNTARA, 2011).

Para Milani (2006), não só o nível de associativismo interfere na participação como também o desenho institucional das arenas decisórias e até mesmo a orientação ideológica do Executivo. Mesmo diante de PP(s) que realmente valorizam a participação popular, o autor argumenta ser constante a falta de resultados satisfatórios devido à "apatia política dos cidadãos" e o "descaso popular por assuntos políticos".

Em decorrência dessa preocupação com a burocracia, entre outras coisas, surge a questão da reforma do Estado frente ao federalismo e à opção pela descentralização. Os impactos desse movimento sobre as $\mathrm{PP}(\mathrm{s})$ podem ser vislumbrados nos trabalhos cita- dos a seguir. Guimarães (2003) argumenta que a CF/88, representando a redemocratização, estabeleceu uma forte preocupação com a reforma do Estado e a descentralização, o que não impediu a existência de conflitos entre as esferas de governo. A autora afirma, inclusive, que o conflito de interesses é inerente ao federalismo e que deve ser considerado quando existirem PP(s) de descentralização. Por exemplo, para driblar o confronto entre Executivo e Legislativo, os órgãos administrativos do primeiro editam as chamadas Normas Operacionais Básicas, ou simplesmente NOB(s), para regulamentar as $\mathrm{PP}(\mathrm{s})$ de saúde. Nesse sentido, o conflito de interesses pode ser observado nos processos decisórios intrínsecos à operacionalização das transferências de recursos, evidenciando a existência de um jogo de poder na implementação das $\mathrm{PP}(\mathrm{s})$ criadas pela descentralização. Esses apontamentos pautam-se na análise da área de saúde, mas, como vimos, embora as $\mathrm{PP}(\mathrm{s})$ tenham pontos de convergência, o elemento área de atuação promove distinções importantes. Isso não impede a afirmação da autora de que existe uma "natureza política da descentralização", como o próprio princípio da complementaridade. Por essa razão, o arranjo institucional das PP(s) descentralizadoras deveria conter a preocupação com o controle dos conflitos políticos entre as subunidades da federação, isto é, precisa reconhecer a existência da "barganha federativa" decorrente da busca pela otimização da relação recursos financeiros versus encargos governamentais.

Analisando por outro ângulo a relação entre federalismo e PP(s), Arretche (2002) ressalta o fato de a literatura afirmar que a estrutura federativa impede ou dificulta as mudanças, porque tanto as "relações verticais" como as "horizontais" aumentam "o poder de veto das minorias" e "a dispersão da autoridade política". Mas a autora afirma que esse poder de veto ${ }^{8}$ não se concretiza da forma exposta anteriormente, já que constituem obstáculos superáveis para a implementação

\footnotetext{
${ }^{8}$ A Câmara Municipal funciona como "ponto de veto" das ações do Executivo, mas regras constitucionais também podem ser consideradas "ponto de veto". No caso das empresas de saneamento estatais estudadas pela autora, que requeriam autorização dos municípios para se privatizarem e para modificar a possibilidade do veto, era necessária uma emenda constitucional.
} 
da agenda formulada. A agenda de reformas não implica arenas decisórias com custos de transação mais elevados, como o Congresso; por exemplo, quanto às políticas de habitação, saneamento, saúde e educação, apenas nesta última a estratégia da União pautou-se na necessidade de aprovação de emenda constitucional; no restante criou uma "estrutura de incentivos" que estimulava os governos subnacionais a aderirem às reformas. Como visto, a ideia de "arrancos de adesão" está ligada à regulamentação por meio de atos executivos exercidos pela burocracia, como ocorre com as NOB(s) editadas pelo Ministério da Saúde, visto que as regras de implementação são elaboradas por aquela. Da mesma forma, embora de modo menos complexo, ocorre na relação entre Executivo e Legislativo Municipal, já que apenas os recursos e a lei são liberados ou criados pelo Legislativo, enquanto as normas operacionais podem nem ser formalizadas e conduzidas com ampla discricionariedade.

\section{Estruturas organizacionais e modelos possíveis}

Todo governo municipal é organizado em Secretarias e/ou Departamentos de administração de acordo com cada tema e sub-tema relativos à vida dos munícipes, nuns com uma estrutura mais enxuta, e noutros mais detalhada. Políticas públicas de geração de renda geralmente são vinculadas à Secretaria de Desenvolvimento ou, dependendo do tipo de nicho de mercado no qual pretendem atuar, a outras secretarias como a de meio ambiente, infraestrutura e comércio. De acordo com o enfoque poderiam, ainda, ser atribuídas a uma Secretaria de Assistência Social, como frequentemente ocorre. Mas esse tipo de PP, que impulsiona a formação de empreendimentos cooperativos, estrutura-se em alguns pilares básicos. Não importa apenas a reinserção no mercado, mas, talvez até mais do que isso, também o processo de formação cooperativa e capacitação profissional. Se uma Secretaria de governo é capaz de realizar essas três etapas e constituir uma equipe flexível o suficiente para atender a essa demanda, veremos que aparentemente não atrapalha o fato de haver concentração de poderes em um só setor da administração. Caso contrário, se apenas um desses vértices é atendido, os problemas de institucionalização, de acordo com características próprias de cada grupo, parecem mais eminentes. Por vezes, ocorre o investimento não só na formação em Economia Solidária para o público-alvo, mas também para a burocracia. É o caso, por exemplo, da SENAES (SINGER, 2009).

O tipo de assistência e assessoria fornecida pela municipalidade também interfere no grau de institucionalização do modelo. Se a relação é de cunho assistencialista, as possibilidades de a ação se institucionalizar são diminuídas, na medida em que não permite que os indivíduos internalizem o hábito de cooperar e autogerir o empreendimento em questão. Se a Administração Municipal oferece assistência técnica capaz de estimular a qualificação dos indivíduos atendidos e faz com que eles desenvolvam um tipo de "massa crítica local", por sua vez, ajuda a institucionalizar a ação de cooperação e autogestão. Mas isso só é possível quando o programa de geração de renda qualifica os indivíduos para atuarem no eixo que compõe a atividade na qual eles buscam inserir-se. Se, ao contrário disso, a Administração Municipal oferece um funcionário ou então um consultor para resolver, ainda que temporariamente, os problemas que surgem, o público atendido "perde a possibilidade" de aprender a lidar com esses problemas. Da mesma forma, quando a municipalidade estabelece uma relação assistencialista, há que se esperar uma maior dependência por parte dos indivíduos com relação ao atendimento fornecido pelo projeto, além de impedir o desenvolvimento autônomo deles. Existem várias formas de se criar essa relação que pode, em um caso extremo, transformar-se em dependência. Uma delas é o fornecimento constante de cesta básica, outra é o pagamento permanente das despesas fixas como o aluguel, a energia elétrica, o transporte da produção, o fornecimento de funcionários e assim por diante.

Essas ações podem e até devem ser programadas como emergenciais e tendo prazo certo para se extinguirem, já que os empreendimentos cooperativos precisam ser, minimamente, economicamente viáveis para se manterem. Para justificar esse tratamento, podemos recorrer a Amartya Sen (2000) e sua discussão acerca das capacidades de titularidade das quais dispõem esse público e a necessi- 
dade de reforçá-las, ainda que na ausência de desenvolvimento. Afinal, o fornecimento de subsídios e a alavancagem da atividade com base nas facilidades que a Administração Pública pode promover por meio do Poder de Polícia (na sua não aplicação) e da disponibilidade de algumas liberdades que lhes são permitidas como concessões, isenções e doações é amplamente praticado para sociedades anônimas e sociedades limitadas em geral, por que então não o seria para cooperativas?

Existe também variação do modelo quanto à estrutura do programa de geração de renda, preocupação com a formação das cooperativas e não só com a reinserção no mercado. Para se formar uma cooperativa, é necessário, dentre outras coisas, que os futuros cooperados participem de um curso versando sobre autogestão e cooperação econômica. Aparentemente, esses cursos auxiliam, ainda que morosamente, no sentido de familiarizar os indivíduos com essa nova realidade. De acordo com essa premissa, os cursos de cooperativismo também ajudam a institucionalizar a ação. Sendo assim, aqueles municípios que encarregam uma dada secretaria ou departamento para tratar apenas da questão da formação cooperativa, além de uma equipe de funcionários qualificados para atender a essa demanda, a princípio teriam mais chances de contribuir para a institucionalização da ação cooperativa. A formação de uma ITCP (Incubadora Tecnológica de Cooperativas Populares), por exemplo, não determina o sucesso de um empreendimento cooperativo ou sua falência, mas contribui no sentido de demonstrar o empenho e interesse público com relação a essa temática9.

Um exemplo interessante é a chamada cooperativa-escola ${ }^{10}$, sempre atrelada às Escolas Técnicas Federais, responsáveis por formar os técnicos agrícolas e criada como solução para o gerenciamento de recursos e condições de

\footnotetext{
${ }^{9}$ Os governos têm demonstrado uma preferência em terceirizar esse serviço, contratando ITCP(s) universidades ou ONG(s) especializadas nesse tema, para não desencadear "inchaço da máquina pública" em seus quadros funcionais. Lembrando que a ES não se resume ao formato de cooperativas.

${ }^{10}$ De acordo com Marques e Love (1993), a experiência da cooperativa-escola remonta a 1932, mas sua regulamentação só ocorreu em 1967. Além disso, apenas em 1982 esse tipo de cooperativa adquiriu o mesmo tratamento legal destinado às cooperativas tradicionais.
}

ensino, estimulada por um tipo de PP. Essas escolas conseguem conjugar teoria e aplicação prática, não apenas com relação à produção, mas também quanto à administração, educação e treinamento. Tal experiência ajuda a consolidar a rede já existente de cooperados, além de reafirmar e estimular os princípios cooperativistas ${ }^{11}$. Assim sendo, a cooperativaescola possibilita a prática do cooperativismo para os alunos que primeiro estudaram essa disciplina num plano teórico, cuja matéria acompanha os alunos desde a sua entrada no curso e, quando se matriculam na escola, eles já podem tornar-se cooperados ${ }^{12}$, se assim desejarem. O sistema da cooperativa-escola, inclusive o regime de tutela, transição e cooperação com o governo, ajuda a pensar uma nova possibilidade de ITCP para os governos municipais, sem a necessidade de uma estrutura apartada do todo, contemplando os recursos de que a Administração Municipal dispõe e suas necessidades, por exemplo, quanto à compra de alimentos para as refeições oferecidas nas escolas, insumo e mão de obra. A cooperativa-escola fundamentalmente ajuda a disseminar e fixar pela prática os princípios do cooperativismo. Uma alternativa mais simples está presente naqueles municípios que optam por inserir na grade curricular dos alunos do ensino fundamental uma disciplina específica sobre cooperativismo ${ }^{13}$, com o objetivo de estimular a familiaridade e, com ela, a prática. Com a municipalização do ensino fundamental essa possibilidade tornou-se mais efetiva nessa área.

Um dado que me parece também determinante na ação do Executivo é o interesse e o apoio da Câmara de Vereadores.

\footnotetext{
${ }^{11}$ Ressalva seja feita ao fato de que a cooperativa dos alunos tem a tutela de um professor orientador e a assessoria de um profissional da contabilidade contratado pela própria cooperativa. Outra questão é a existência de um contrato entre a cooperativa e a escola técnica, de acordo com o qual a última fornece insumos para a primeira em troca de alimentos.

${ }^{12}$ A escola cede, em regime de comodato, terras, equipamentos, instalações. Essa experiência constitui-se num período de transição para o cooperativismo de fato, porque ainda existe a tutela do professor. Entretanto, não existe cobrança quanto ao máximo de eficiência econômica porque a cooperativa está atrelada ao ensino, sem comprometê-lo.

${ }^{13}$ Além do mais, essa seria uma opção interessante, visto que, atualmente, o setor que mais recebe recursos dentro da administração pública é o de educação.
} 
O interesse é diferente do apoio e pode até surgir em decorrência deste, mas implica a necessidade de cumprir um objetivo que não se limita ao apoio político em si, podendo, inclusive, surgir num grupo de oponentes. Para medir esse interesse, tem-se claramente como fator determinante a sensibilidade do eleitor com relação a esses mesmos projetos. Na verdade, se eles são projetos de forte apelo popular e se resultam, por exemplo, na criação de um "nicho eleitoral", os vereadores têm alguma motivação no sentido de participar ou ao menos demonstrar-lhes apoio político, representando-os junto ao Executivo e seus órgãos administrativos. Às vezes até mesmo tornando-se cooperado ou colocando assessores e familiares para cumprir essa função ${ }^{14}$.

Outro dado não menos importante, principalmente com relação à contribuição para a continuidade do processo, diz respeito à regulamentação dos projetos de geração de renda, bem como do programa no qual eles se enquadram. Essa regulamentação não impede por completo alterações no programa em si, mas prevê e estabelece diretrizes impedindo ou dificultando que, com a mudança de governo, todas as ações vinculadas ao mandato anterior sejam canceladas ou extintas. É o caso do Plano Plurianual (PPA), por exemplo, que adentra o primeiro ano do governo subsequente e exerce claramente esse papel ao impor uma continuidade no cumprimento dos planos do governo que o formulou. Além dos elementos enfatizados, outro elemento interveniente é o apelo eleitoral durante a campanha para prefeito e o fato de esses projetos constarem nos programas de governo, como relatado anteriormente.

Depois de passarmos pela questão do conceito, da dinâmica e do "estado da arte" dos estudos de PP(s) no Brasil, do desenho institucional destas, das relações intergovernamentais e da burocracia, discutiremos agora a relação entre elas e o orçamento público.

\section{Orçamento municipal: tipos de despesa e capacidade de gastos}

O orçamento municipal é composto por recursos de origens diversas, tais como:

$14 \quad$ Esse fato foi diagnosticado nos municípios estudados em Alcântara (2008). tributos em razão da propriedade, circulação de mercadorias; serviços; taxas diversas; transferências estaduais, transferências federais e verbas vinculadas. Com tais recursos, a gestão pública efetua a distribuição de acordo com necessidades como: gastos com pessoal, prestação de serviços, manutenção da estrutura física, assessoria, obras e programas/ projetos específicos. Sabendo-se que todo orçamento municipal é "fechado" tendo como base a aprovação do Plano Plurianual (PPA), a relevância de um projeto dentro de uma dada gestão pode ser vislumbrada a partir da averiguação acerca da dotação orçamentária que lhe é sugerida. Isso não implica dizer que o valor destinado indique a importância de um projeto para a gestão, mesmo porque o PPA segue do Executivo para a Câmara para ser aprovado, revisto ou reprovado, podendo ser modificado nesse trajeto e ainda dispor de verbas de suplementação, que podem ser solicitadas pelo prefeito no decorrer da gestão. A demanda popular, expressa por meio do interesse político e, principalmente, do retorno eleitoral, na maioria das vezes, direciona a grandeza referente a essa dotação. Mas isso não é uma regra geral. Um dos carros-chefe de campanha pode ter um custo reduzido frente a obras que não tiveram tanta importância durante a corrida eleitoral. Da mesma forma, podem perder espaço junto ao próprio grupo, quando este consegue se eleger.

Em Alcântara (2008) investiguei junto aos entrevistados quais eram as fontes de receita com as quais eles contavam para desenvolver o programa de ES, e assim, mensurar ou vislumbrar as possibilidades de expansão do modelo para outros municípios, indicando suas características centrais. Nos dois casos estudados, houve um desencontro quanto a algumas informações obtidas. Num município não foi mencionado nenhum valor específico para tais programas e noutro as informações fornecidas pelos diretores e o secretário foram distintas. Em suma, aparentemente não existe dotação orçamentária específica para esse setor, contando-se apenas com os meios de ação municipal e, principalmente, recursos vinculados ao gabinete do prefeito. Esse é um quesito muito importante no que concerne à efetividade das PP(s). 


\section{Considerações finais}

Existem modelos de gestão que, no máximo, recriam um ou dois elementos dos citados anteriormente, fazendo com que, aparentemente, o projeto se torne insuficiente com relação à capacidade de institucionalizar um hábito. Dificilmente conseguimos verificar por meio de um modelo abstrato qual o peso de cada variável exposta anteriormente. Muito menos é possível determinar que tipo de relação causal obrigatoriamente ocorre entre as variáveis combinadas em contextos diversos. Mas conseguimos confirmar, por meio de pesquisa de campo, e a bibliografia disponível também é farta em exemplos neste sentido, que a simples existência de algumas dessas características favorece substancialmente a institucionalização de um dado comportamento e, quando combinadas, o resultado tende a ser ainda mais favorável. Não se trata, contudo, de traçar um posicionamento normativo na postura científica, mas o gestor de PP(s) necessariamente possui essa característica e deverá atentar para essas considerações.

No caso brasileiro, a Lei 12.690 de 2012 renovou consideravelmente a discussão, ao aproximar os direitos cooperativos de alguns institutos do direito trabalhista. Resta, ainda, averiguar os impactos dessa nova política pública, de cunho federal, que interfere diretamente em todas as políticas públicas municipais sobre esse assunto específico.

Como pudemos verificar, a confecção de $\mathrm{PP}(\mathrm{s})$ depende não apenas de pressão popular e interesse político, mas também de disposições normativas constitucionais e infraconstitucionais. Num Estado Democrático de Direito é praticamente impossível pensar a ação política como algo espontâneo e livre, dependendo apenas da criatividade, genialidade, lógica ou vontade política. Política pública, então, depende de normatização, recursos e meios de ação municipal como qualquer outra ação do Executivo.

\section{Referências}

ALCÂNTARA, Fernanda H. C. A municipalização das políticas públicas de geração de renda e a institucionalização das práticas cooperativas. 2008. Tese (Doutorado em Sociologia) - Instituto Universitário de Pesquisas do Rio de Janeiro (IUPERJ), Rio de Janeiro, 2008.
. As reformas legais e o processo de descentralização. Revista de Sociologia e Política, Curitiba, PR, v. 19, n. 39, p. 197-210, jun. 2011.

2005.

Economia solidária. São Paulo: Arte\&Ciência,

Municipalização e políticas públicas: a regulamentação como projeto e a prática social como resposta. CSOnline, Juiz de Fora, MG, ano 4, n. 10, p. 245- 263, ago. 2010.

. Políticas públicas municipais: poderes e poderes. Perspectivas em Políticas Públicas, Belo Horizonte, MG, v. III, n. 05, p. 24-42, jan./jun. 2010.

ARAÚJO, Paulo Magalhães. Racionalidade, instituições e normas: uma análise sobre a ação coletiva e a estabilidade das escolhas sociais. Isegoria - Ação Coletiva em Revista, Madri, ano 01, v. 01, n. 01, mar./ago. 2011.

ARRETCHE, Marta. Dossiê agenda de pesquisa em políticas públicas. Revista Brasileira de Ciências Sociais, São Paulo, v. 18, n. 51, p. 7-9, fev. 2003.

Federalismo e relações intergovernamentais no Brasil. Dados - Revista de Ciências Sociais, Rio de Janeiro, v. 45, n. 3, p. 431-458, 2002.

BONFIM, Washington L. de S.; SILVA, Irismar N. da. Instituições políticas, cidadania e participação: a mudança social ainda é possível. Revista de Sociologia e Política, Curitiba, PR, n. 21, p. 109-123, 2003.

CÔRTES, Soraya M. Vargas. O governo do Estado como protagonista da regionalização e da participação. Caderno CRH, Salvador, BA, v. 16, n. 39, p. 83-103, jul./ dez. 2003.

COUTO, Cláudio; ABRUCIO, Fernando. O segundo governo FHC: coalizões, agendas e instituições. Tempo Social, São Paulo, v. 15, n. 2, nov. 2003.

FARIA, Carlos A. P. de. Idéias, conhecimento e políticas públicas: um inventário sucinto das principais vertentes analíticas recentes. Revista Brasileira de Ciências Sociais, São Paulo, v. 18, n. 51, p. 21-29, fev. 2003.

FREITAS, Alair F. de; FREITAS, Alan F. de. Empreendimentos induzidos por políticas públicas: reflexões a partir do Programa de Combate à Pobreza Rural (PCPR) em Minas Gerais. Interações, Campo Grande, MS, v. 12, n. 2, p. 255-265, jul./dez. 2011.

GUIMARÃES, Maria do Carmo. Processo decisório e conflitos de interesse na implementação da descentralização da saúde: um estudo das instâncias colegiadas na Bahia. Caderno CRH, Salvador, BA, n. 39, p. 105-132, jul./dez. 2003.

MARQUES, P. V.; LOVE, H. G. Cooperativa-escola nas escolas técnicas agrícolas. Sci. Agric., Piracicaba, SP, v. 50, n. 3, p. 509-516, out./dez. 1993.

MILANI, Carlos. Políticas públicas locais e participação na Bahia: o dilema gestão versus política. Sociologias, Porto Alegre, RS, ano 8, n. 16, p. 180-214, jul./ dez. 2006.

SAMPAIO, Juliana; ARAÚJO JR., José Luís. Análise das políticas públicas: uma proposta metodológica para o estudo no campo da prevenção em Aids. Revista Brasileira de Saúde Materno-Infantil, Recife, PE, v. 6, n. 3, p. 335-346, jul./set. 2006. 
SEN, Amartya. Desenvolvimento como liberdade. São Paulo: Companhia das Letras, 2000.

SETZLER, Mark. Recursos socioeconômicos, capital sociocultural e conhecimento político como determinantes da formulação de política públicas locais no Brasil. Caderno CRH, Salvador, BA, n. 39, p. 133-160, jul./dez. 2003.

SINGER, Paul. Políticas Públicas da Secretaria Nacional de Economia Solidária no Ministério do Trabalho e
Emprego. Mercado de Trabalho, n. 39, p. 42-48, maio 2009. SOUZA, Celina. "Estado do campo" da pesquisa em políticas públicas no Brasil. Revista Brasileira de Ciências Sociais, São Paulo, v. 18, n. 51, p. 15-20, fev. 2003a.

Políticas públicas: questões temáticas e de pesquisa. Caderno CRH, Salvador, BA, n. 39, p. 11-24, 2003 b.

Políticas públicas: uma revisão da literatura. Sociologias, Porto Alegre, RS, ano 8, n. 16, p. 20-45, jul./ dez. 2006. 